\title{
Copper-catalysed asymmetric allylic alkylation of alkylzirconocenes to racemic 3,6-dihydro-2H-pyrans
}

\author{
Emeline Rideau and Stephen P. Fletcher ${ }^{*}$
}

\author{
Full Research Paper \\ Address: \\ Department of Chemistry, Chemistry Research Laboratory, University \\ of Oxford, 12 Mansfield Road, Oxford, OX1 3TA, UK, Fax: \\ $+44(1865) 285002$ \\ Email: \\ Stephen P. Fletcher ${ }^{*}$ - stephen.fletcher@chem.ox.ac.uk \\ * Corresponding author \\ Keywords: \\ allylic alkylation; asymmetric catalysis; copper; design of experiments; \\ dynamic kinetic asymmetric transformation; heterocycles; Schwartz \\ reagent
}

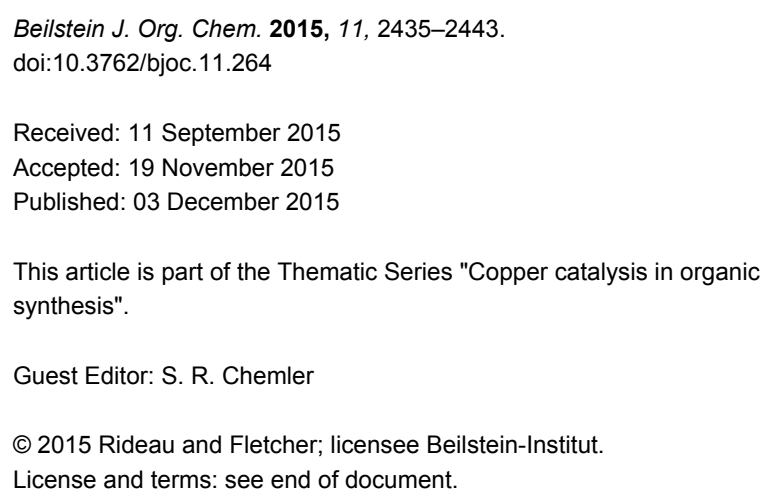

\begin{abstract}
Asymmetric allylic alkylation is a powerful reaction that allows the enantioselective formation of $\mathrm{C}-\mathrm{C}$ bonds. Here we describe the asymmetric alkylation of alkylzirconium species to racemic 3,6-dihydro- $2 \mathrm{H}$-pyrans. Two systems were examined: 3-chloro-3,6dihydro-2H-pyran using linear optimization (45-93\% ee, up to 33\% yield, 5 examples) and 3,6-dihydro- $2 H$-pyran-3-yl diethyl phosphate with the assistance of a design of experiments statistical approach ( $83 \%$ ee, $12 \%$ yield). ${ }^{1} \mathrm{H}$ NMR spectroscopy was used to gain insight into the reaction mechanisms.
\end{abstract}

\section{Introduction}

Asymmetry is found in many natural products and biologically active molecules. Using racemic starting materials to synthesize enantiomerically enriched products is a powerful and underdeveloped strategy [1-4]. In some cases transition metalcatalysed asymmetric allylic alkylation (AAA) reactions [5-7] can be used in dynamic kinetic asymmetric transformations (DYKAT) [8-15] to provide single enantiomer products from racemic starting materials. Mechanistically some of these have been shown to occur by direct enantio-convergent transformations [16-18]. We have developed $\mathrm{Cu}$-catalysed asymmetric conjugate additions of alkylzirconium reagents generated in situ by hydrometallation of terminal alkenes [19-25], and recently demonstrated that zirconium nucleophiles may undergo highly enantioselective copper-catalysed AAAs to racemic cyclic allyl halides, such as $\mathbf{1}$ (Scheme 1a) [26,27].

Tetrahydropyrans are a common motif in natural products and pharmaceuticals and are useful synthetic intermediates. However, the direct asymmetric derivatization of pyrans is rare [28] and enantiomerically enriched tetrahydropyrans are often obtained by ring-closing methods $[29,30]$. To extend our previously reported DYKATs beyond all-carbon electrophiles we decided to examine 3-chloro-3,6-dihydro-2H-pyran (2a, Scheme $1 \mathrm{~b}$ ). This was envisaged to be a challenging substrate. 
a) Previously reported Cu-AAA

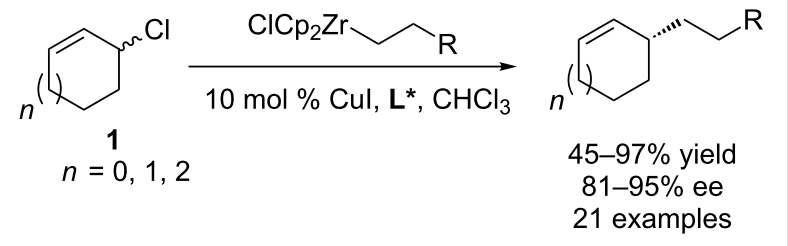

b) This work<smiles>[X]C1C=CCOC1</smiles>

2

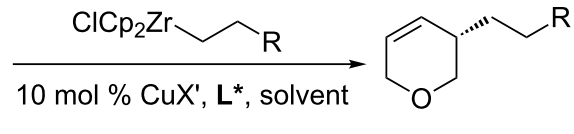

3
Scheme 1: Previously reported Cu-AAA of alkylzirconium reagents to racemic allyl chlorides [26] and this work.

The presence of oxygen in the ring would modify the electronics, and likely the reactivity, of the starting material. The oxygen lone pairs on $\mathbf{2 a}$ could potentially interact with the copper-catalyst or alkyl metal nucleophiles.

\section{Results and Discussion}

We first examined the in situ hydrometallation/AAA of 4-phenyl-1-butene (4) to racemic 3-chloro-3,6-dihydro- $2 \mathrm{H}$ pyran (2a, Table 1). Interestingly, no product was formed using our previously reported conditions for AAA to racemic carbocyclic substrates (CuI, ligand $\mathbf{A}, \mathrm{CHCl}_{3}$, Table 1, entry 1) [26] and only unreacted starting material was recovered. Different $\mathrm{Cu}$ salts were examined (Table 1, entries 2-7) and more strongly electron withdrawing counterions were found to provide the desired product, with $\mathrm{CuClO}_{4}$ giving the best ee ( $70 \%$ ee, Table 1 , entry 3 ). A solvent screen lead us to the conclusion that chlorinated solvents are best $\left(\mathrm{CH}_{2} \mathrm{Cl}_{2}(70 \%\right.$ ee $)$ and $\mathrm{CHCl}_{3}(67 \%$ ee), Table 1, entries 7 and 10, respectively). Extensive examination of phosphoramidite ligands (for example, Table 1, entries 2 and 11-13) did not improve the ee. We then tested many different additives (TMSCl, AgOTf, borates, $\mathrm{ZrCl}_{4}, \mathrm{Si}(\mathrm{OEt})_{4}$, etc, for example Table 1, entries 14-18). Using $\mathrm{B}(\mathrm{OiPr})_{3}$, which presumably acts as a Lewis acid, improved the ee to $80 \%$ (Table 1 , entry 18 ) and so we re-examined different ligands using $\mathrm{CuClO}_{4}$ in $\mathrm{CH}_{2} \mathrm{Cl}_{2}$ with $\mathrm{B}(\mathrm{OiPr})_{3}$ (Table 1, entries 19-21). Derivatives of ligand $\mathbf{B}$ were tested and ligand $\mathbf{F}$ gave $83 \%$ ee (Table 1, entry 21 ), while electronically similar $\mathbf{E}$ was much less selective (47\% ee, Table 1 , entry 20). The effects of concentration, temperature and catalyst loading were also investigated (not shown) with no improvement on the enantioselectivity.

After extensive optimization, the highest enantiomeric excess obtained was only $83 \%$ ee and so we decided to examine other leaving groups (Table 2). Like allyl chloride 2a, allyl bromide 2b gave no desired product when using our previously reported conditions [26] (Table 2, entry 2). The use of $\mathbf{2 b}$ also only gave low ee when using the conditions optimized above (38\% ee, Table 2, entry 1). Allyl acetate $2 \mathrm{c}$ did not give the desired product under any conditions examined, however, allyl phosphate 2d was found to provide $\mathbf{5}$ with good selectivity (77\% ee, Table 2, entry 5). 3,6-Dihydro-2H-pyran-3-yl diethyl phosphate (2d) was also the only substrate to react using our previously reported AAA conditions ( $\mathrm{CuI}$, ligand $\mathbf{A}, \mathrm{CHCl}_{3}$ ) [26], albeit with poor enantioselectivity ( $29 \%$ ee, Table 2 , entry 6$)$.

Design of experiments (DoE) [31-37] is a powerful tool for efficient screening and is commonly used in industry, since traditional one-factor-at-a-time optimization poorly covers the available parameter space and may not locate the most optimal conditions. As DoE rapidly explores the response space efficiently and can reveal interdependence of factors at no extra experimental cost, we decided to briefly examine DoE in this complex asymmetric transformation. We note that there are important limits to this investigation. Understanding what interactions give rise to asymmetric induction (particularly in transformations where mechanisms are not understood) is extremely challenging, and it is not obvious how to parameterize the multiple variables present in key factors such as ligand structure [38].

Nevertheless, a Principal Component Analysis using JMP ${ }^{\circledR}$ 12.1.0 (SAS) in 3 waves was carried out using $\mathbf{2 d}$ as the starting material. In each experiment, the most promising variables were chosen based on results from previously published methods, the procedure optimised for 2a (above), and the results of previous waves. The first wave was as a third factorial design with 3 categories: Ligand $(\mathbf{A}, \mathbf{B}, \mathbf{C}, \mathbf{F}$ and $\mathbf{G})$, counter-ion $\left(\mathrm{ClO}_{4}{ }^{-}, \mathrm{I}^{-}\right.$ and $\left.\mathrm{OTf}^{-}\right)$and solvent $\left(\mathrm{CH}_{2} \mathrm{Cl}_{2}, \mathrm{Et}_{2} \mathrm{O}\right.$ and TBME, Table 1, entries 1-17; • Figure 1, for more details see Supplorting Information File 1).

This first DoE study suggested that neither CuI nor TBME were good fits for the reaction (both consistently giving low ee). The combination of $\mathrm{CuOTf}$ in $\mathrm{CH}_{2} \mathrm{Cl}_{2}$ gave the best enantioselectivity (up to $83 \%$ ee, Table S1 entry 3 , Supporting Information File 1) with ligand G. Unlike with $\mathbf{2 a}, \mathrm{CuClO}_{4}$ did not give high ee with $\mathbf{2 d}$; the highest value obtained was $43 \%$ ee (Table S1, entry 14). Interestingly $\mathrm{Et}_{2} \mathrm{O}$ gave mixed results with some low (e.g., 1\% ee, Table S1, entry 1) and moderate (e.g., $56 \%$ ee, Table S1, entry 6) ee values obtained.

Based on those results, a second wave of DoE was designed as a $6^{\text {th }}$ factorial design with 4 factors: Ligand $(\mathbf{G}, \mathbf{H}, \mathbf{I}, \mathbf{J})$, counter-ion (OTf and $\left.\mathrm{NTf}_{2}\right)$, solvent $\left(\mathrm{CH}_{2} \mathrm{Cl}_{2}, \mathrm{Et}_{2} \mathrm{O}\right.$ and $\left.\mathrm{CHCl}_{3}\right)$ and TMSCl equivalent (0,1 and 5) (Table S1, entries 
Table 1: Asymmetric alkylation to 3-chloro-3,6-dihydro-2H-pyran (2a) a<smiles>C=CCCc1ccccc1O[Mg]O[Mg]</smiles><smiles>C[C@@H](c1ccccc1)N([C@H](C)c1ccccc1)P(Oc1ccc2ccccc2c1)Oc1ccc2ccccc2c1-c1ccccc1</smiles><smiles>CC(C)N(c1ccccc1)P(Oc1ccc2ccccc2c1)Oc1ccc2ccccc2c1-c1ccccc1</smiles>

B<smiles>CC(C)N(C(c1cccc2ccccc12)c1cccc2ccccc12)P(Oc1ccc2ccccc2c1-c1cccc2ccccc12)Oc1cccc2ccccc12</smiles>

C<smiles>CCOP(Oc1ccc2ccccc2c1-c1c(O)ccc2ccccc12)N(C(C)C)C(c1cccc(C(F)(F)F)c1)c1cccc(C(F)(F)F)c1</smiles><smiles></smiles>

E<smiles>COc1ccccc1C(c1ccccc1OC)N(POc1ccc2ccccc2c1-c1cccc2ccccc12)C(C)C</smiles>

F

\begin{tabular}{|c|c|c|c|c|c|}
\hline Entry & Copper & $L^{*}$ & Solvent & Additive & $e e^{b}$ \\
\hline 1 & Cul & A & $\mathrm{CHCl}_{3}$ & & $\mathrm{NP}$ \\
\hline 2 & $\mathrm{CuClO}_{4}$ & A & $\mathrm{CH}_{2} \mathrm{Cl}_{2}$ & & $68 \%$ \\
\hline 3 & $\mathrm{CuClO}_{4}$ & B & $\mathrm{CH}_{2} \mathrm{Cl}_{2}$ & & $70 \%$ \\
\hline 4 & CuOTf & B & $\mathrm{CH}_{2} \mathrm{Cl}_{2}$ & & $64 \%$ \\
\hline 5 & $\mathrm{CuNTf}_{2}$ & B & $\mathrm{CH}_{2} \mathrm{Cl}_{2}$ & & $52 \%$ \\
\hline 6 & CuTC & B & $\mathrm{CH}_{2} \mathrm{Cl}_{2}$ & & $12 \%$ \\
\hline 7 & $\mathrm{CuSbF}_{6}$ & B & $\mathrm{CH}_{2} \mathrm{Cl}_{2}$ & & NP \\
\hline 8 & $\mathrm{CuClO}_{4}$ & B & $\mathrm{Et}_{2} \mathrm{O}$ & & $55 \%$ \\
\hline 9 & $\mathrm{CuClO}_{4}$ & B & Me-THF & & $38 \%$ \\
\hline 10 & $\mathrm{CuClO}_{4}$ & B & $\mathrm{CHCl}_{3}$ & & $67 \%$ \\
\hline 11 & $\mathrm{CuClO}_{4}$ & C & $\mathrm{CH}_{2} \mathrm{Cl}_{2}$ & & $53 \%$ \\
\hline 12 & $\mathrm{CuClO}_{4}$ & D & $\mathrm{CH}_{2} \mathrm{Cl}_{2}$ & & $36 \%$ \\
\hline 13 & $\mathrm{CuClO}_{4}$ & $E$ & $\mathrm{CH}_{2} \mathrm{Cl}_{2}$ & & $12 \%$ \\
\hline 14 & $\mathrm{CuClO}_{4}$ & B & $\mathrm{CH}_{2} \mathrm{Cl}_{2}$ & TMSCI & $73 \%$ \\
\hline 15 & $\mathrm{CuClO}_{4}$ & B & $\mathrm{CH}_{2} \mathrm{Cl}_{2}$ & $\mathrm{Si}(\mathrm{OEt})_{4}$ & $63 \%$ \\
\hline 16 & $\mathrm{CuClO}_{4}$ & B & $\mathrm{CH}_{2} \mathrm{Cl}_{2}$ & $\mathrm{Ti}(\mathrm{OiPr})_{4}$ & $25 \%$ \\
\hline 17 & $\mathrm{CuClO}_{4}$ & B & $\mathrm{CH}_{2} \mathrm{Cl}_{2}$ & $\mathrm{AlCl}_{3}$ & $15 \%$ \\
\hline 18 & $\mathrm{CuClO}_{4}$ & B & $\mathrm{CH}_{2} \mathrm{Cl}_{2}$ & $\mathrm{~B}(\mathrm{OiPr})_{3}$ & $80 \%$ \\
\hline 19 & $\mathrm{CuClO}_{4}$ & C & $\mathrm{CH}_{2} \mathrm{Cl}_{2}$ & $\mathrm{~B}(\mathrm{OiPr})_{3}$ & $78 \%$ \\
\hline 20 & $\mathrm{CuClO}_{4}$ & $E$ & $\mathrm{CH}_{2} \mathrm{Cl}_{2}$ & $\mathrm{~B}(\mathrm{OiPr})_{3}$ & $47 \%$ \\
\hline 21 & $\mathrm{CuClO}_{4}$ & $\mathbf{F}$ & $\mathrm{CH}_{2} \mathrm{Cl}_{2}$ & $\mathrm{~B}(\mathrm{OiPr})_{3}$ & $83 \%$ \\
\hline
\end{tabular}

aConditions: 4-phenyl-1-butene ( 2.5 equiv), $\mathrm{Cp}_{2} \mathrm{ZrHCl}$ (2.0 equiv), $\mathbf{2 a}$ (1.0 equiv), CuL* as specified ( 0.1 equiv), additive as specified (1.0 equiv), in specified solvent $(2.0 \mathrm{~mL})$, room temperature. ${ }^{b}$ ee determined by HPLC. NP = no product. For more information on procedures see Supporting Information File 1. 
Table 2: Effect of leaving groups. ${ }^{\text {a }}$

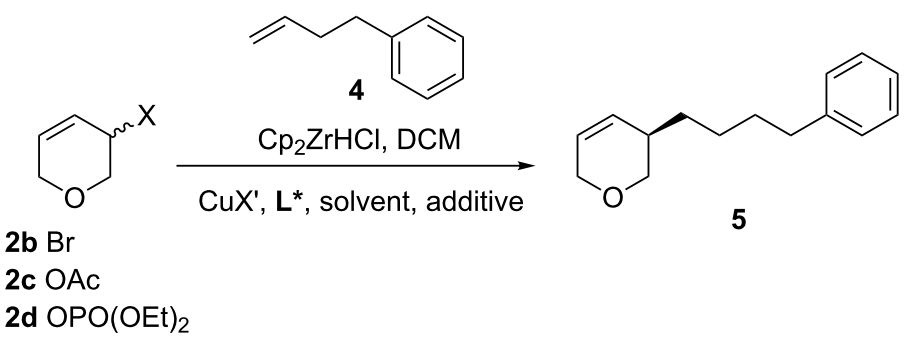

\begin{tabular}{|c|c|c|c|c|c|c|}
\hline Entry & $x$ & Copper & $L^{*}$ & Solvent & Additive & $e e^{b}$ \\
\hline 1 & $\mathrm{Br}$ & $\mathrm{CuClO}_{4}$ & $\mathbf{F}$ & $\mathrm{CH}_{2} \mathrm{Cl}_{2}$ & $\mathrm{~B}(\mathrm{O} i \mathrm{Pr})_{3}$ & $38 \%$ \\
\hline 2 & $\mathrm{Br}$ & Cul & A & $\mathrm{CHCl}_{3}$ & & NP \\
\hline 3 & OAc & $\mathrm{CuClO}_{4}$ & $\mathbf{F}$ & $\mathrm{CH}_{2} \mathrm{Cl}_{2}$ & $\mathrm{~B}(\mathrm{OiPr})_{3}$ & NP \\
\hline 4 & OAc & Cul & A & $\mathrm{CHCl}_{3}$ & & NP \\
\hline 5 & $\mathrm{OPO}(\mathrm{OEt})_{2}$ & $\mathrm{CuClO}_{4}$ & $\mathbf{F}$ & $\mathrm{CH}_{2} \mathrm{Cl}_{2}$ & $\mathrm{~B}(\mathrm{OiPr})_{3}$ & $77 \%$ \\
\hline 6 & $\mathrm{OPO}(\mathrm{OEt})_{2}$ & Cul & A & $\mathrm{CHCl}_{3}$ & & $29 \%$ \\
\hline
\end{tabular}

aConditions: 4-phenyl-1-butene (2.5 equiv), $\mathrm{Cp}_{2} \mathrm{ZrHCl}$ (2.0 equiv), 2 (1.0 equiv), CuL*(0.1 equiv), additive (1.0 equiv), in solvent (2.0 mL), room temperature. ${ }^{b}$ ee determined by HPLC. NP $=$ no product. For more information on procedures see Supporting Information File 1.

$18-30, \diamond)$. As mixed results were obtained with $\mathrm{Et}_{2} \mathrm{O}$, we decided to investigate it more thoroughly. This second study emphasizes the intrinsic challenge of finding optimum conditions in complex asymmetric reactions. Whereas CuOTf seems to work best with $\mathrm{CH}_{2} \mathrm{Cl}_{2}$ as a solvent, $\mathrm{CuNTf}_{2}$ gave better enantioselectivity in $\mathrm{Et}_{2} \mathrm{O}$. $\mathrm{CHCl}_{3}$ consistently provided lower enantioselectivity than $\mathrm{CH}_{2} \mathrm{Cl}_{2}$. In the small selection of ligands examined, $\mathbf{G}$ generally gave better results.

We designed a final study to investigate the role of various equivalents of additive (TMSCl and $\left.\mathrm{B}(\mathrm{OiPr})_{3}\right)$ with $\mathrm{CuOTf}$ and $\mathrm{CuNTf}_{2}$ in their respective favoured solvents $\left(\mathrm{CH}_{2} \mathrm{Cl}_{2}\right.$ and $\mathrm{Et}_{2} \mathrm{O}$ ) (Table $\mathrm{S} 1$, entries $\left.31-38, \boldsymbol{\nabla}\right)$. $\mathrm{B}(\mathrm{OiPr})_{3}$ significantly lowered the ee ( $44 \%$ ee, Table S1, entry 33$)$. The influence of $\mathrm{TMSCl}$ on the reaction was highly dependent on the other reaction parameters; $\mathrm{CuNTf}_{2}$ in $\mathrm{Et}_{2} \mathrm{O}$ with no additive gave $67 \%$ ee (Table S1, entry 34), while adding 1 equiv of TMSCl gave a slight improvement (73\% ee, Table S1, entry 35) but no further improvement was observed by adding more $\mathrm{TMSCl}$ ( 5 equiv, $74 \%$ ee, Table S1, entry 36 ). On the other hand, using 1 equiv of TMSCl with $\mathrm{CuOTf}$ in $\mathrm{CH}_{2} \mathrm{Cl}_{2}$ did not modify the ee $(81 \%$ ee, Table S1, entry 32), while adding 5 equiv of TMSCl was detrimental to enantioselectivity (60\% ee, Table S1, entry 31$)$.

Despite our efforts to optimise this second system, the highest enantioselectivity obtained was $83 \%$ ee, which is the same as for allyl chloride $\mathbf{2 a}$. It became clear that when using alkylzirconocene nucleophiles and $\mathrm{Cu}$ catalysis, derivatised 3,6dihydro- $2 H$-pyrans are difficult to obtain in high enantiomeric excess. Moreover, both optimised systems gave poor yield; $25 \%$ yield with $100 \%$ conversion from allyl chloride $2 \mathrm{a}$ and $17 \%$ yield with $31 \%$ conversion from allyl phosphate $\mathbf{2 d}$.

Various alkenes were examined using the allyl chloride 2a system (Scheme 2). The reaction showed tolerance in functional groups such as $\mathrm{CF}_{3}(6,75 \%$ ee $) \mathrm{Cl}(7,77 \%$ ee $)$, and cyclohexane ( $\mathbf{8}, 88 \%$ ee). Electron rich allyl silane could also be used to introduce a TMS group $(\mathbf{9}, 93 \%$ ee), but all the yields were poor.

To investigate why we obtained such poor yields, and possibly shed light onto the reaction mechanism, we decided to follow both reactions in time using in situ NMR spectroscopy (Figure 2 and Figure 3). Reactions were carried out as normal, but in deuterated solvents and mixed in an NMR tube (see Supporting Information File 1). Ethylene was used as the alkylzirconium precursor as it greatly simplifies the NMR spectra. Spectra were recorded at regular intervals over time where relative concentrations are based on integration of the best resolved ${ }^{1} \mathrm{H}$ signal for each species and calibrated accordingly.

Through these kinetic studies, it is clear that the allyl chloride 2a system fails because the starting material dimerises to give 11 as the major reaction product $(60 \%$ isolated yield $30 \mathrm{~mol} \%$ by NMR) (Figure 2). This is consistent with the observed $\approx 100 \%$ conversion but low product yields. Presumably $\mathbf{1 1}$ arises from the homocoupling of allyl chloride $\mathbf{2 a}$, possibly through a $\pi$-allyl-Cu intermediate [39-43]. Although 


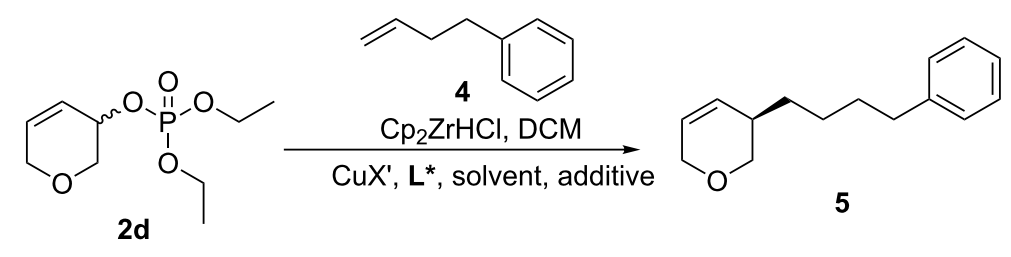<smiles>CC(C)N(C1CCc2ccccc21)P(=O)(Oc1ccc2ccccc2c1)Oc1cccc2ccccc12</smiles>

G<smiles>CC(C)N(POc1ccc2ccccc2c1-c1cccc2ccccc12)C1CCc2ccccc21</smiles>

H<smiles>O=[PH](Oc1ccc2ccccc2c1)c1c(OP(=O)(c2ccccc2)N(C2CCCCC2)C2CCCCC2)ccc2ccccc12</smiles>

I<smiles>CC(c1ccccc1)N([C@H](C)c1ccccc1)P(Oc1ccccc1)c1ccc2ccccc2c1-c1ccccc1</smiles>

$\mathbf{J}$

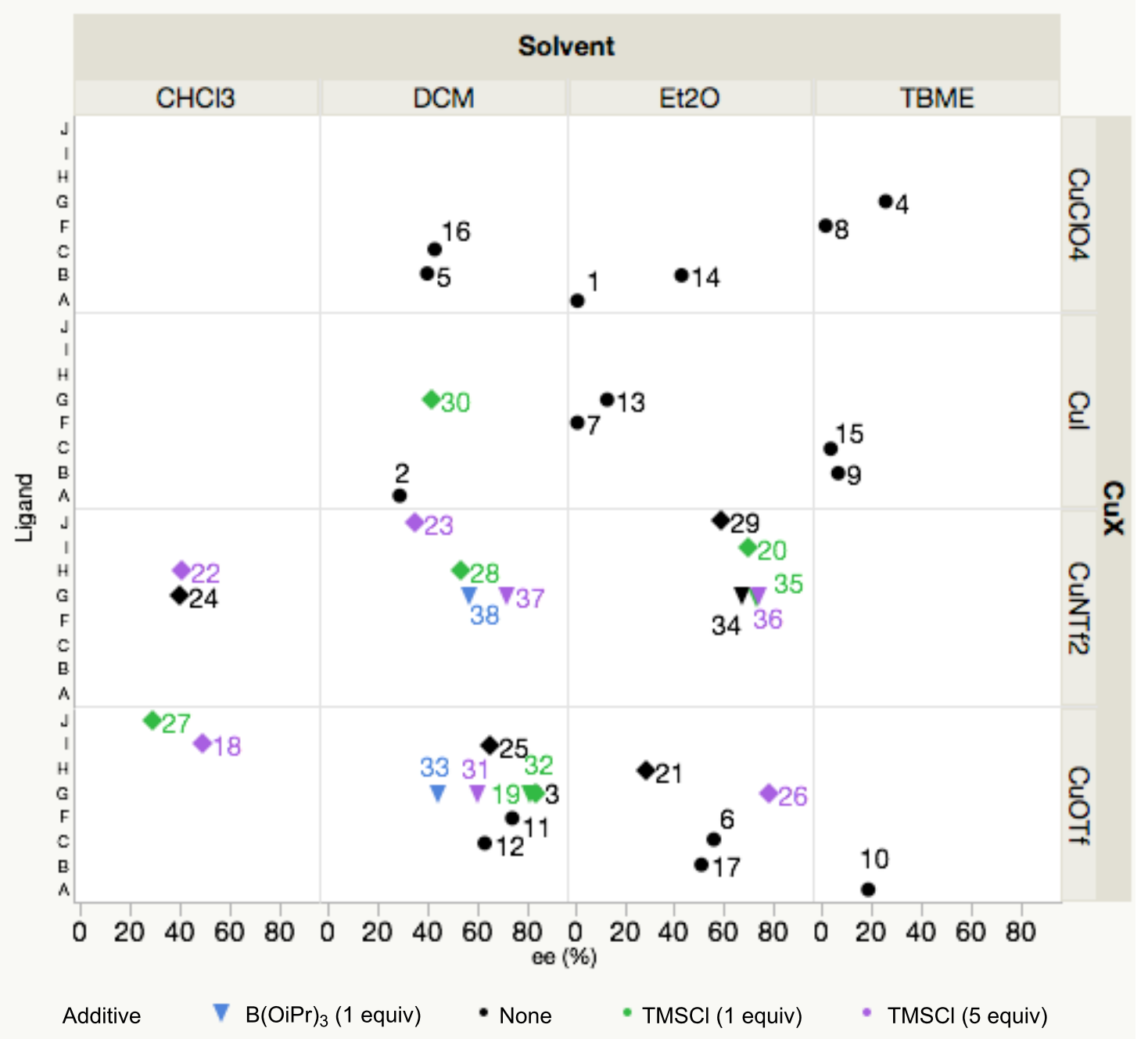

Figure 1: DoE from 3,6-dihydro-2H-pyran-3-yl diethyl phosphate (2d). Conditions: 4-phenyl-1-butene (2.5 equiv), $\mathrm{Cp}_{2} \mathrm{ZrHCl}$ (2.0 equiv), 2d (1.0 equiv), CuL* as specified ( 0.1 equiv), additive as specified (1.0 equiv or 5.0 equiv), in specified solvent $(2.0 \mathrm{~mL})$, room temperature. ee determined by HPLC. For more information on the procedures see Supporting Information File 1. • (wave 1, entries 1-17), (wave 2, entries 18-30),

$\boldsymbol{\nabla}$ (wave 3, entries 31-38). 

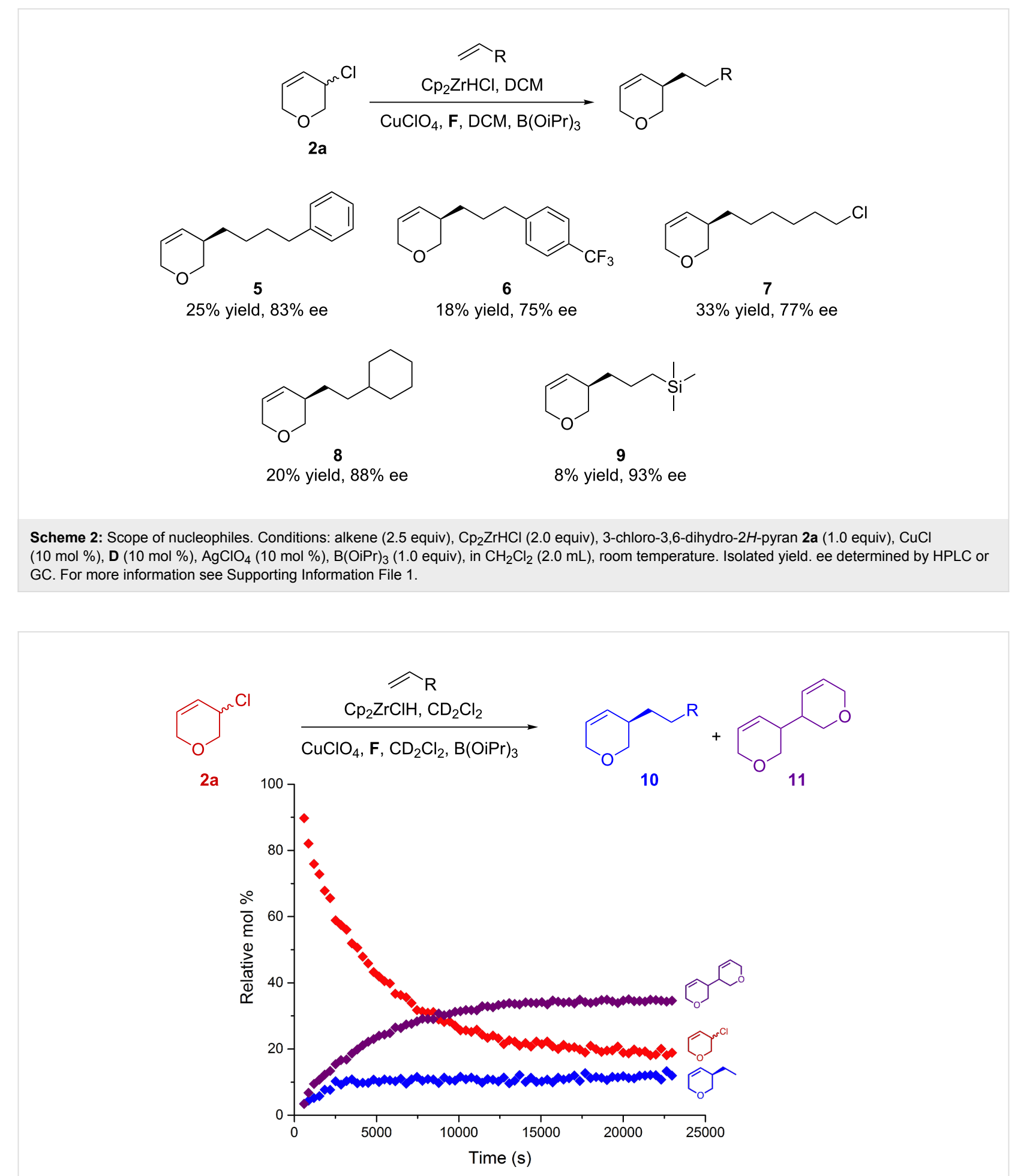

Figure 2: Reaction kinetics as monitored by in situ ${ }^{1} \mathrm{H}$ NMR spectroscopy from 3-chloro-3,6-dihydro-2H-pyran (2a).

both the conditions and leaving groups differ in the two reactions it is not clear why $\mathbf{2 a}$, but not $\mathbf{2 d}$, dimerizes. $\mathbf{1 1}$ can exists as 3 isomers, a meso compound and two enantiomers. Upon comparison to literature data [44], we concluded that we form a mixture of all three, as a 1:1 mixture of the meso and racemic material. Our samples did not rotate plane polarized light, emphasizing the racemic nature of the sample and suggesting that $\mathbf{1 1}$ is formed in a completely non-selective pathway. 


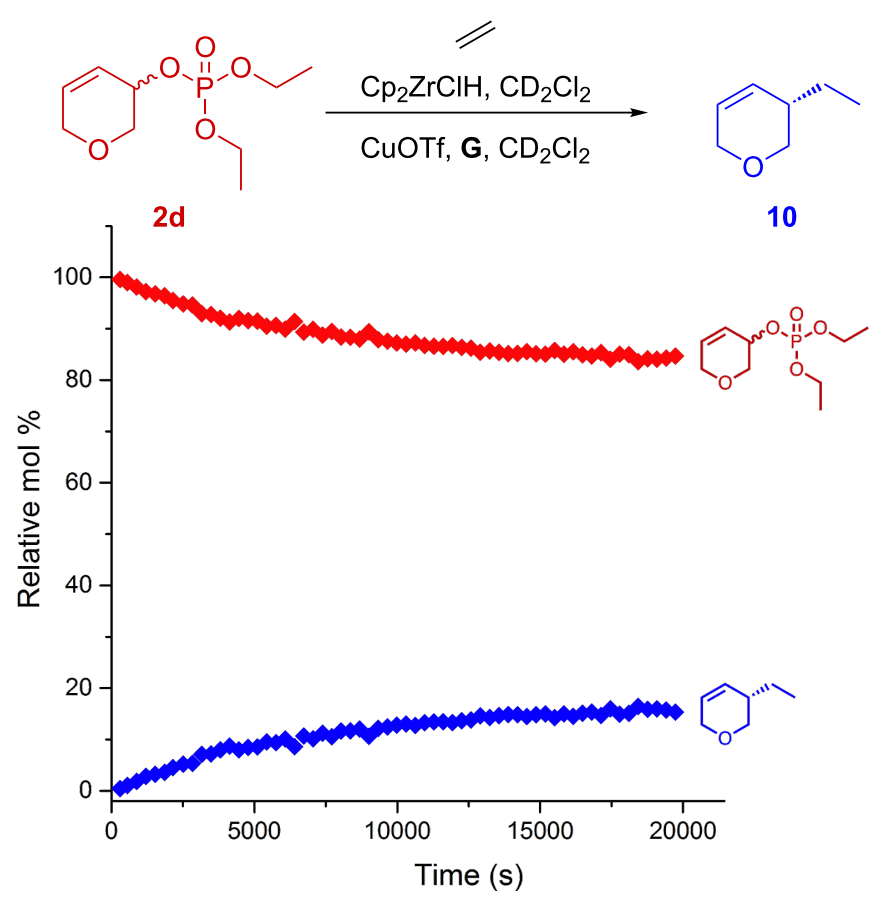

Figure 3: Reaction kinetics as monitored by in situ ${ }^{1} \mathrm{H}$ NMR spectroscopy from 3,6-dihydro-2H-pyran-3-yl diethyl phosphate (2d).

In the case of allyl phosphate $\mathbf{2 d}$, the system appears to lack reactivity and the reaction quickly dies, so that $\mathbf{1 0}$ (Figure 3 ) is formed with poor conversion, and we speculate that the phosphate leaving group inhibits the catalyst which would explain why only $\sim 10 \%$ of product is formed.
To obtain further mechanistic information we followed the ee of these reactions in time (Figure 4 and Figure 5). In the system using chloride $\mathbf{2 a}$, the ee of product $\mathbf{5}$ remains constant throughout the reaction ( $\sim 75 \%$ ee, Figure 4$)$. Starting chloride 2 a was found to be quite robust so that we could also determine its

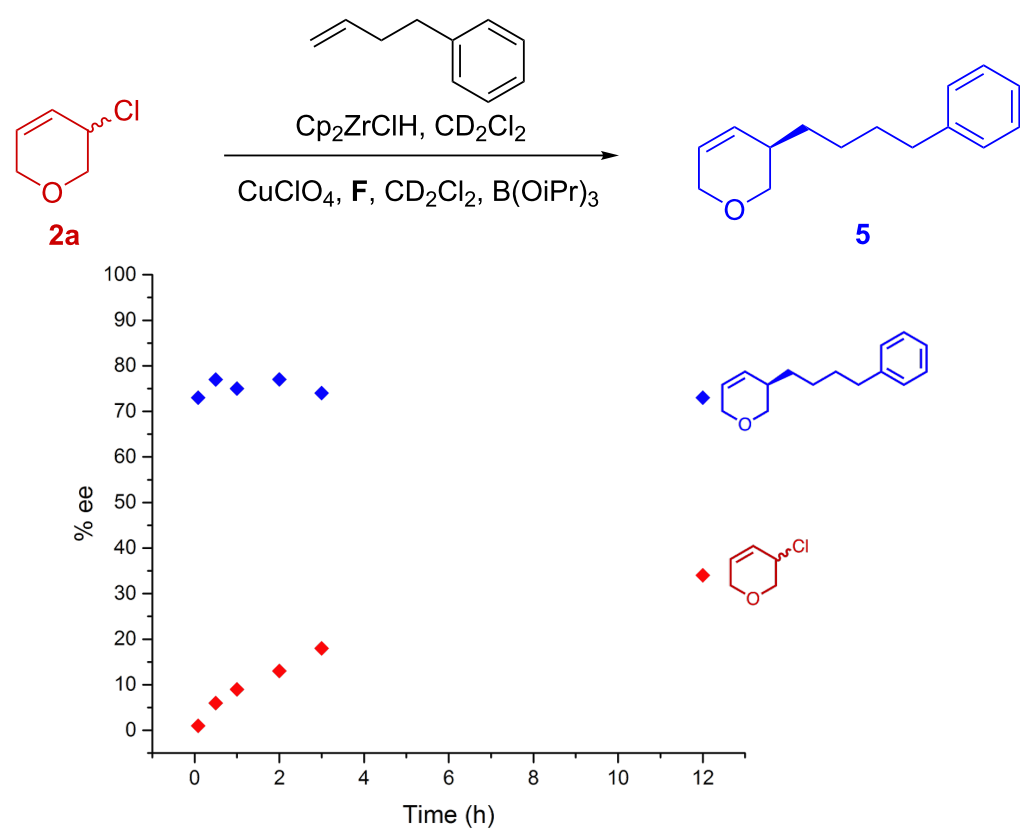

Figure 4: Kinetic ee analysis using $\mathbf{2 a}$. ee of reaction with 3-chloro-3,6-dihydro-2H-pyran (2a) as measured by removing aliquots in time. 

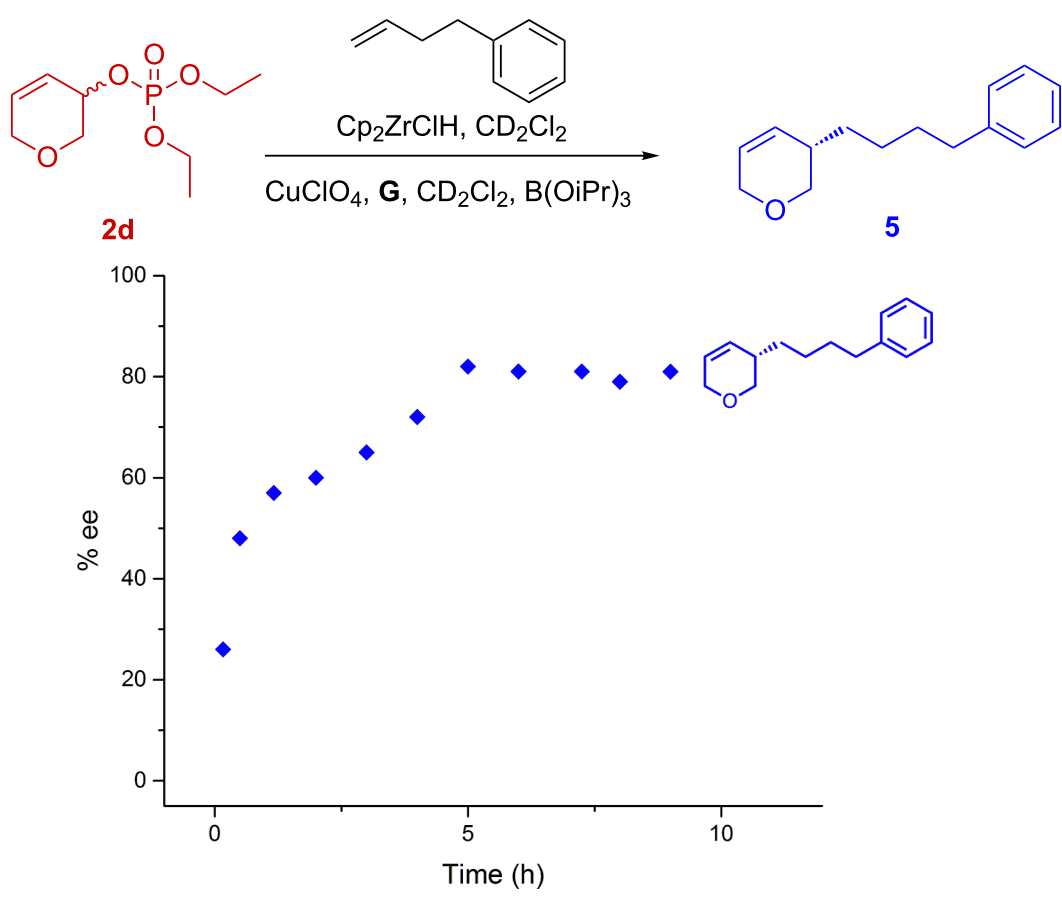

Figure 5: Kinetic ee analysis using $\mathbf{2 d}$. ee of reaction with 3,6-dihydro-2H-pyran-3-yl diethyl phosphate (2d) as measured by removing aliquots in time.

enantiomeric excess during the course of the reaction. Initially 2a is racemic but it becomes scalemic to slowly reach $34 \%$ ee when the reaction is complete ( 12 hours). From these observations and our experimental demonstration that $\mathbf{2 a}$ is much more stable than all-carbocyclic 1, it appears that $\mathbf{2 a}$ undergoes kinetic resolution. However, this system is clearly complicated by the fact that the majority of $\mathbf{2 a}$ is consumed during byproduct 11's formation.

In the phosphate system based on $\mathbf{2 d}$, the ee of product $\mathbf{5}$ was found to increase during the course of the reaction (Figure 5) so that 5 was $\sim 26 \%$ ee after a few minutes, and increased to $\sim 82 \%$ ee after 5 hours. Unfortunately, analytical conditions to separate the enantiomers of $\mathbf{2 d}$, so we could measure the enantiomeric excess of this starting material, could not be found. At this stage it is not possible to provide a full mechanistic rationalization of these reactions. It is also not immediately obvious how to improve yields and enantiomeric excesses. The kinetic studies suggest that the two reactions work through very different mechanisms and it strikes us as remarkable how both systems give roughly the same enantioselectivity and poor yield, yet have significantly different pathways.

\section{Conclusion}

The $\mathrm{Cu}$-catalyzed AAA of alkylzirconium reagents to racemic heterocyclic electrophiles was explored. After extensive examination, two different methods for obtaining 3,6-dihydro- $2 \mathrm{H}$ - pyran derivatives with respectable levels of ee $(\approx 83 \%$ ee $)$ were developed. Unfortunately, the yields were poor in both cases. Kinetic studies were performed to help to understand the difficulties associated with these reactions. While we were not able to resolve the issues of yield in these studies, this work reveals remarkable mechanistic diversity in $\mathrm{Cu}$-catalysed asymmetric alkylation reactions to racemic starting materials.

\section{Supporting Information}

\section{Supporting Information File 1}

Additional material.

[http://www.beilstein-journals.org/bjoc/content/ supplementary/1860-5397-11-264-S1.pdf]

\section{Acknowledgements}

The authors thank the EPSRC (EP/H003711/1) for financial support.

\section{References}

1. Faber, K. Chem. - Eur. J. 2001, 7, 5004. doi:10.1002/1521-3765(20011203)7:23<5004::AID-CHEM5004>3.0.C O;2-X

2. Vedejs, E.; Jure, M. Angew. Chem., Int. Ed. 2005, 44, 3974. doi:10.1002/anie.200460842

3. Mohr, J. T.; Ebner, D. C.; Stoltz, B. M. Org. Biomol. Chem. 2007, 5, 3571. doi:10.1039/b711159m 
4. Miller, L. C.; Sarpong, R. Chem. Soc. Rev. 2011, 40, 4550 doi:10.1039/c1cs15069c

5. Trost, B. M.; Bunt, R. C. J. Am. Chem. Soc. 1994, 116, 4089 doi:10.1021/ja00088a059

6. Trost, B. M.; Van Vranken, D. L. Chem. Rev. 1996, 96, 395. doi:10.1021/cr9409804

7. Lu, Z.; Ma, S. Angew. Chem., Int. Ed. 2008, 47, 258 doi:10.1002/anie.200605113

8. Huerta, F. F.; Minidis, A. B. E.; Bäckvall, J.-E. Chem. Soc. Rev. 2001, 30, 321. doi:10.1039/b105464n

9. Trost, B. M.; Fandrick, D. R. Aldrichimica Acta 2007, 40, 59.

10. Norinder, J.; Bäckvall, J.-E. Chem. - Eur. J. 2007, 13, 4094. doi:10.1002/chem.200601684

11. Langlois, J.-B.; Alexakis, A. Chem. Commun. 2009, 3868. doi:10.1039/b907722g

12. Langlois, J.-B.; Alexakis, A. Adv. Synth. Catal. 2010, 352, 447. doi:10.1002/adsc.200900790

13. Katcher, M. H.; Doyle, A. G. J. Am. Chem. Soc. 2010, 132, 17402. doi:10.1021/ja109120n

14. Hamilton, J. Y.; Hauser, N.; Sarlah, D.; Carreira, E. M. Angew. Chem., Int. Ed. 2014, 53, 10759. doi:10.1002/anie.201406077

15. Misale, A.; Niyomchon, S.; Luparia, M.; Maulide, N. Angew. Chem., Int. Ed. 2014, 53, 7068. doi:10.1002/anie.201309074

16. Ito, H.; Kunii, S.; Sawamura, M. Nat. Chem. 2010, 2, 972. doi:10.1038/nchem. 801

17. Langlois, J.-B.; Emery, D.; Mareda, J.; Alexakis, A. Chem. Sci. 2012, 3, 1062. doi:10.1039/C2SC00868H

18. Delvos, L. B.; Oestreich, M. Synthesis 2015, 47, 924. doi:10.1055/s-0034-1380157

19. Maksymowicz, R. M.; Roth, P. M. C.; Fletcher, S. P. Nat. Chem. 2012, 4, 649. doi:10.1038/nchem.1394

20. Sidera, M.; Roth, P. M. C.; Maksymowicz, R. M.; Fletcher, S. P. Angew. Chem., Int. Ed. 2013, 52, 7995. doi:10.1002/anie.201303202

21. Maciver, E. E.; Maksymowicz, R. M.; Wilkinson, N.; Roth, P. M. C.; Fletcher, S. P. Org. Lett. 2014, 16, 3288. doi:10.1021/ol501292x

22. Roth, P. M. C.; Fletcher, S. P. Org. Lett. 2015, 17, 912. doi:10.1021/acs.orglett.5b00021

23. Rideau, E.; Mäsing, F.; Fletcher, S. P. Synthesis 2015, 47, 2217. doi:10.1055/s-0034-1379928

24. Caprioglio, D.; Fletcher, S. P. Chem. Commun. 2015, 51, 14866. doi:10.1039/C5CC05805H

25. Maksymowicz, R. M.; Bissette, A. J.; Fletcher, S. P. Chem. - Eur. J. 2015, 21, 5668. doi:10.1002/chem.201405855

26. You, H.; Rideau, E.; Sidera, M.; Fletcher, S. P. Nature 2015, 517, 351. doi:10.1038/nature14089

27. Sidera, M.; Fletcher, S. P. Chem. Commun. 2015, 51, 5044 doi:10.1039/C5CC00421G

28. Morken, J. P.; Didiuk, M. T.; Visser, M. S.; Hoveyda, A. H. J. Am. Chem. Soc. 1994, 116, 3123. doi:10.1021/ja00086a052

29. Fu, G. C.; Nguyen, S. T.; Grubbs, R. H. J. Am. Chem. Soc. 1993, 115, 9856. doi:10.1021/ja00074a085

30. Clark, J. S. Chem. Commun. 2006, 3571. doi:10.1039/b601839d

31. Aggarwal, V. K.; Staubitz, A. C.; Owen, M. Org. Process Res. Dev. 2006, 10, 64. doi:10.1021/op058013q

32. Weissman, S. A.; Anderson, N. G. Org. Process Res. Dev. 2015, 19 , 1605. doi:10.1021/op500169m

33. Owen, M. R.; Luscombe, C.; Lai-Wah; Godbert, S.; Crookes, D. L.; Emiabata-Smith, D. Org. Process Res. Dev. 2001, 5, 308. doi:10.1021/op000024q
34. Chen, J. J.; Nugent, T. C.; Lu, C. V.; Kondapally, S.; Giannousis, P.; Wang, Y.; Wilmot, J. T. Org. Process Res. Dev. 2003, 7, 313. doi:10.1021/op034018g

35. Denmark, S. E.; Butler, C. R. J. Am. Chem. Soc. 2008, 130, 3690. doi:10.1021/ja7100888

36. Arnold, K.; Batsanov, A. S.; Davies, B.; Whiting, A. Green Chem. 2008, 10, 124. doi:10.1039/B712008G

37. Peñafiel, I.; Pastor, I. M.; Yus, M. Eur. J. Org. Chem. 2013, 1479. doi:10.1002/ejoc.201201066

38. Harper, K. C.; Sigman, M. S. J. Org. Chem. 2013, 78, 2813. doi:10.1021/j04002239

39. Yoshikai, N.; Nakamura, E. Chem. Rev. 2012, 112, 2339. doi:10.1021/cr200241f

40. Geurts, K.; Fletcher, S. P.; van Zijl, A. W.; Minnaard, A. J.; Feringa, B. L. Pure Appl. Chem. 2008, 80, 1025. doi:10.1351/pac200880051025

41. Alexakis, A.; Bäckvall, J. E.; Krause, N.; Pàmies, O.; Diéguez, M. Chem. Rev. 2008, 108, 2796. doi:10.1021/cr0683515

42. Harutyunyan, S. R.; den Hartog, T.; Geurts, K.; Minnaard, A. J.; Feringa, B. L. Chem. Rev. 2008, 108, 2824. doi:10.1021/cr068424k

43. Alexakis, A.; Krause, N.; Woodward, S. Copper-Catalyzed Asymmetric Synthesis; Wiley-VCH: Weinheim, 2014. doi:10.1002/9783527664573

44. Maougal, E.; Dalençon, S.; Pearson-Long, M. S. M.;

Mathé-Allainmat, M.; Lebreton, J.; Legoupy, S. Synthesis 2014, 46, 3268. doi:10.1055/s-0034-1378663

\section{License and Terms}

This is an Open Access article under the terms of the Creative Commons Attribution License (http://creativecommons.org/licenses/by/2.0), which permits unrestricted use, distribution, and reproduction in any medium, provided the original work is properly cited.

The license is subject to the Beilstein Journal of Organic Chemistry terms and conditions:

(http://www.beilstein-journals.org/bjoc)

The definitive version of this article is the electronic one which can be found at:

doi:10.3762/bjoc. 11.264 